\title{
Design \& Simulation of Energy Storage Unified Power Quality Conditioner (EUPQC) for Power Quality Improvement
}

\author{
Rayavarapu Pavani ${ }^{1}$, T Srinivasa Rao ${ }^{2}$, P Anil Kumar ${ }^{3}$ \\ ${ }^{1}$ M.Tech Scholar, Department of EEE, Avanthi Institute of Engineering \& Technology, Narsipatnam, \\ Visakhapatnam, Andhra Pradesh-531113, \\ ${ }^{2}$ Associate Professor, Department of EEE, Avanthi Institute of Engineering \& Technology, Narsipatnam, \\ Visakhapatnam, Andhra Pradesh-531113, \\ ${ }^{3}$ Assistant Professor, Department of EEE, Avanthi Institute of Engineering \& Technology, Narsipatnam, \\ Visakhapatnam, Andhra Pradesh-531113,
}

\begin{abstract}
Rapid consumption of energy from conventional sources can be limited by connecting more no. of distributed generation systems with the support of smart grid technology. But the impact of variation in DG power out putted may lead to power quality problems in the distributed system in which it is connected. In addition to this power system faults, non- linear loads and non-linear characteristics of converter circuits used in DG s further deteriorate quality of the power. Implementation of UPQC in the network itself solves the problems addressed but crowding of more no of DG in the network will suppress the effect of UPQC. However energy storage system integration can suppress the large power fluctuations outputted by DGs. In this paper energy storage based unified power quality conditioner (EUPQC) has been implemented using fuggy logic controller. For energy storage ultra (Super) capacitor has been used for fast rate of charging and discharging. The performance of the implemented UPQC with fuggy logic controller is compared with PI controller with the MATLAB simulation.
\end{abstract}

Keywords: Distributed Generator(DG), Energy Storage Unified Power Quality Conditioner(EUPQC)

\section{INTRODUCTION}

The distributed generation technology as the supporting technology of smart grid changes quickly recently. In power distribution network system with DGs, the fluctuation of power outputted by DGs would result in voltage quality problems easily, such as voltage sag, voltage fluctuation and voltage interruption, etc. Together with voltage quality problems brought by power distribution network self-defect, voltage quality is of an increasingly serious problem. Consequently, a more effective measurement to improve power quality is urgently needed. The research on influence of voltage quality in the local power distribution network caused by the high penetration of DGs, has become one of hotspot issues in the research of scholars both domestic and abroad [1-3].

For voltage quality improvement of distributions network with the high penetration of DGs, Distributed Flexible AC Transmission Systems (DFACTS) focus on the user side and the flexibility and power quality control of distribution network system. At the same time, the function of UPQC is considered the most comprehensive and effective in the DFACTS devices [4-6]. Meanwhile, that stability of the DG system and power quality can be enhanced by configuring energy storage unit, has been an academic consensus. The role of the energy storage in improving voltage quality has been analyzed in the Reference [7-10]. In more detail, the working principle of the stability control based on energy storage principle has been described, but also its mathematical model is established in Reference [9]. Through analyzing the example based on Superconducting Magnetic Energy Storage (SMES) and Flywheel Energy Storage, the conclusion that providing the power system with appropriate active and reactive power compensation enhances the stability of AC transmission system effectively is verified.

According to the voltage quality problems caused by large numbers of DGs which being interconnected to in $\mathrm{MV} / \mathrm{LV}$ distribution network and self-defect of distribution network, the paper presents a novel UPQC structure based on super capacitor fast energy storage. The accuracy and reliability of the control strategy for this device are verified by both the experimental result and the detail principle simulation. Then through analyzing the practical application of such kind of UPQC in distribution network, we effectively realize the improvement of the voltage quality. 


\section{POWER QUALITY PROBLEMS IN DISTRIBUTION NETWROK WITH HIGH PENETRATION OF DGS}

In distribution network with high penetration of DGs, enough power support is used to restraint output power fluctuation. The power could be supplied by energy storage technology, which includes two aspects: one is high efficient mass storage, and the other is fast and efficient energy conversion. Energy storage technology applied in power system can realize peak load shifting and system reserve demand reduction. Meanwhile, it would provide technical support for reducing network power loss and improving power quality. Super capacitor storage is normally used for smoothing the power of short duration, high power load or used in high peak power situation such as high power DC motor starting and dynamic voltage restorer. When it comes to voltage sags or instantaneous disturbance, Super capacitor storage technology is able to improve the power supply and quality. Thus, this technology is suitable for solving power quality problems in distribution network with high penetration of DGs [11-12].

Custom power technology, based on power electronic technology, could provide power supply up to reliability and stability level which users required in MV/LV distribution network system. UPQC, with feature of series compensation and parallel compensation being integrated together, has been considered as the most full featured and effective one of all DFACTS technologies so far. To improve power quality of distribution network with the high penetration of DGs, developing custom power technology based on UPQC, which can inject active power during the voltage regulation and integrate to reactive compensation, is a feasible strategy.

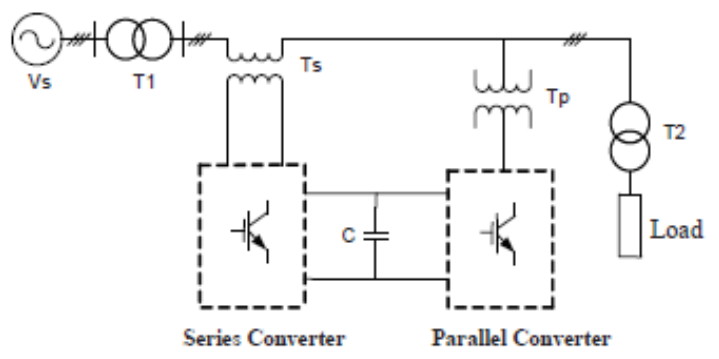

Fig 1 Structure Scheme of UPQC

Traditional UPQC used in power distribution system, integrating series compensation voltage principle and parallel compensation voltage principle in one device, can compensate three-phase asymmetric and harmonicon both mains supply voltage and nonlinear loads. UPQC is composed of the main circuit shown in Fig. 1, including series and parallel PWM converter, and the control circuit.
There are two basic control strategies, i.e. direct control scheme and indirect control scheme. Direct control scheme means series converter is controlled as sinusoidal current source to isolate voltage disturbance comes from grid and load. And parallel converter is controlled as sinusoidal voltage source to avoid load reactive power, load harmonic current and unbalance from being injected into grid. On the other side indirect control scheme means series converter works as a non-sinusoidal voltage source, outputting compensation voltage which offsets grid voltage distortion and fundamental deviation, accordingly it ensures load voltage being rated sinusoidal voltage. Meanwhile, parallel converter works as an non-sinusoidal current source, outputting reactive power and harmonic current which offset reactive load power and load harmonic current, accordingly it could make the injected current be sinusoidal and running under unit power factor by compensating reactive power and harmonic current [13]. Indirect control scheme by researched more common is mainly discussed in this paper.

With the series and parallel PWM converter topology, three phase four-leg circuit structure implements both three-phase and single phase structure, as a result, it is more flexible and versatility. And three-phase control systems can drive unbalanced loads as a result of three phases being mutually independent [14]. Therefore, it chooses the three-phase four-leg circuit structure as the topology of power quality improving device

In view of the above, this paper presents a kind of three phase four-wire power quality conditioning device based on fast energy storage named Energystorage UPQC (EUPQC) aiming for power quality problems in distribution network with high penetration of DGs.

\section{STRUCTURE OF EUPQC}

As shown in Fig. 2, the main circuit system structure of EUPQC includes series converter, parallel converter, booster and discharge unit which consisting of super capacitor energy storage and DC/DC converter, outputting power transformer $T_{s} A \sim T_{s} C$ of series converter, output filters $L_{s}$ and $C_{s}$ of series converter and inductance $L_{p}$ of parallel converter [5]. The electric interfaces A1, B1, C1, and $\mathrm{N} 1$ connect distribution network source and the A2, B2, C2, and N2 connect various loads. Two sets of three-phase four-leg converter respectively compose the series and parallel converters of the EUPQC. The series converter output enters into distribution network via LC filter and transformer in series, while the parallel device output enters into distribution network with filter inductance in parallel. The switching sequence could be shown in Fig. 2. When EUPQC accesses to distribution network and sets to work, the DC bus voltage equals 
to that of the super capacitor bank. Then close contactors KMp2, 380V AC power supply charges to the dc side via pre-charge resistance $\mathrm{R} 1$ and parallel converter. When charging completes, close $\mathrm{KMp} 1$, and break KMp2 and DC/DC converter starts to work. Adjust the DC side voltage to nominal reference level 690V. Detect unbalanced degree and harmonic content of mains supply voltage and load current in load side, in order that parallel converter could be put into operation when over ranging problem happens. And when voltage problems like voltage sag and swell happen to mains supply, series converter will be put into operation and output compensation voltage until the problems are solved. Then series converter quits working and the SCRA, SCRB and SCRC bypass.

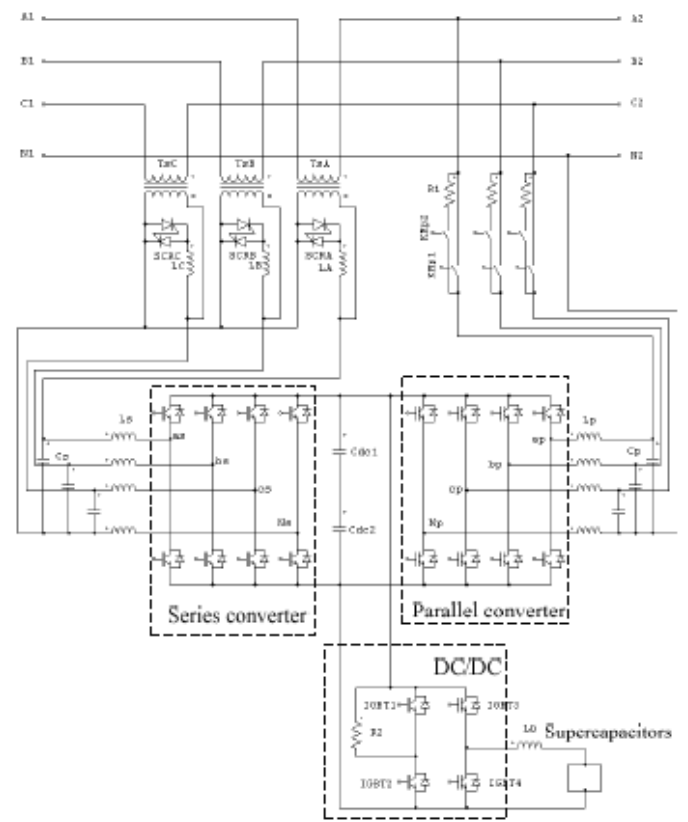

Fig 2. Main Circuit System Circuit of EUPQC

The single phase structure schematic diagram of EUPQC is illustrated in Fig. 3. Series converter output voltage vector to compensate voltage unbalance and harmonic of power supply side. Parallel converter is used to solve power quality problems in load side, such as unbalance and harmonic of nonlinear load including reactive compensating and current harmonic. Super capacitor energy storage and DC /DC converter buffer reactive power, exchange and provide energy for voltage compensation. As a result, decoupling series converter and parallel converter is implemented. Moreover, voltage quality problems of power interruption, which beyond the reach of traditional UPQC, can be resolved successfully.

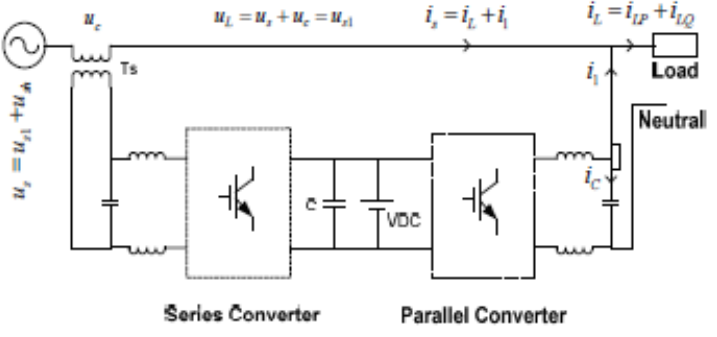

Fig 3. The Single Phase Structure Schematic of EUPQC

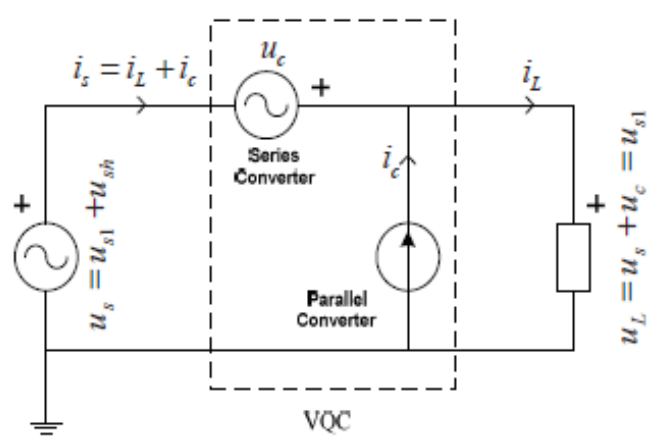

Fig 4. Control Schematic of EUPQC

The ultimate purpose of EUPQC control is to keep load voltage on a constant level and be sinusoidal feature, compensate load reactive power and harmonic and ensure power supply has unity power factor characteristic in all circumstances. As is the control schematic of EUPQC shown in Fig. 4, series converter works as a non-sinusoidal voltage source, outputting compensation voltage $U_{c}$ which offsets grid voltage distortion and fundamental deviation, accordingly it ensures load voltage $U L$ being rated sinusoidal voltage. Meanwhile, shunt converter works as a non-sinusoidal current source, outputting reactive power and harmonic current $i_{c}$ which offset reactive load power and load harmonic current, accordingly it could make the injected current $i_{s}$ be sinusoidal by compensating reactive power and harmonic current. And the angle between the injected voltage $u_{s}$ and the injected current $i_{s}$ is zero at the moment, namely the power factor in grid side is unity [15].

\section{CONTROL STRATEGY OF EUPQC}

The control of EUPQC mainly includes three aspects: the control of series converter, the control of parallel converter and the control of DC bus voltage. In control strategy diagram of series converter shown in Fig. 5, Usa, Usb, Usc are distribution network three-phase voltage respectively. Through software phase-locked loop, we could get $\sin \rceil t$ and $\cos \rceil t$, which is essential to $d q$ rotary transformation. And then we perform $d q$ transform and $d q$ inverse transform on three phase standard voltage to make it in-phase with mains 
supply voltage. Then subtract the distribution network unbalance voltage from this standard voltage to get three phase reference compensation voltage * ca $U,{ }^{*} c b U, * c c U$. Compare reference voltages with three phase actual compensation voltage $U_{c a}, U_{c b}, U_{c c}$, and constitute closed loop control by using a PI regulator. Specifically, in SPWM mode three phase driving signal of series converter is generated, consequently series converter is controlled to output corresponding voltage vector to compensate. The control of the forth leg of series converter is aiming to keep load zero sequence voltage to zero, which function is implemented through closed loop control with feed-forward control for voltage constituted by a PI regulator. Symbols ULa, ULb, ULc in Fig.5 represent three-phase load voltage respectively.

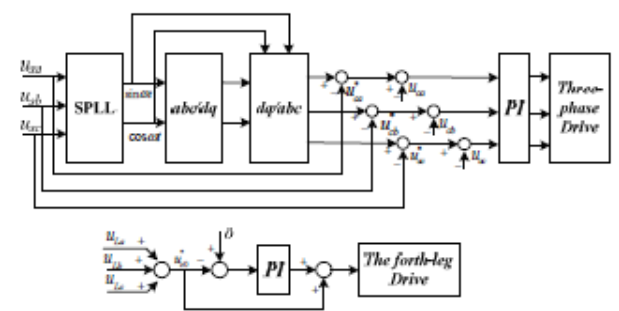

Fig 5 Series Converter Control Strategy Diagram

As parallel converter control strategy diagram shown In Fig.6, perform $d q$ transform on three phase load current $i L a, i L b, i L c$. Then let the transformed current pass low-pass filter to generate active component $i \mathrm{~d}$ and reactive component $i \mathrm{q}$. Perform $d q$ inverse transform on these two components to get fundamental component of three phase load current. Subtract load current from this standard current to get three phase reference compensation current * ica, *icb, *icc . Compare the reference currents with three phase actual compensation current ica, icb, icc, and constitute closed loop control by using a PI regulator. The same as the series converter control mode, in SPWM mode three phase driving pulse signal of parallel converter is generated, consequently parallel converter is controlled to output corresponding current vector to compensate. The control of the forth leg of shunt converter is aiming to keep load zero sequence current to zero, which function is implemented through closed loop control constituted by a PI regulator. Symbols isa, isb, isc in Fig. 6 represent three-phase power supply current respectively. Parallel converter can realize reactive compensation by controlling reactive component $i q$. If $i q=0$, then all reactive power of the load is provided by parallel converter.

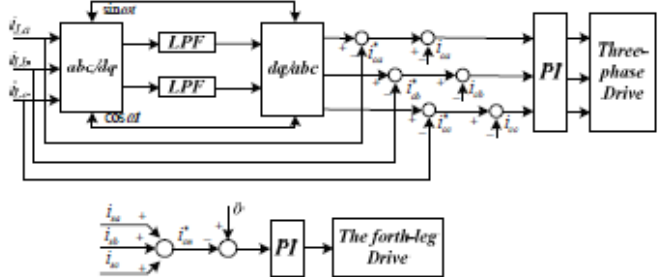

Fig 6. Parallel Converter Control Strategy Diagram

DC side of EUPQC, consisting of bidirectional DC-DC converter based on super capacitor fast energy storage, is able to solve problems of deeper voltage sag and voltage instantaneous interruption. Fig. 7 illustrates control strategy of DC/DC converter. After comparing reference voltage $U_{d e f}$ with DC bus voltage $U_{d}$, the two voltages pass through closed loop PI control and then compared by limited driver to generate PWM signal. They could drive IGBT3 and IGBT4 in Fig. 2 respectively to implement the control of DC/DC converter. And then use the output to maintain $U_{d}$ at a stable level. The function of discharge circuit comprising IGBT1 and IGBT2 could avoid over tension happens to DC bus voltage $U_{d}$. To ensure a high-quality product, diagrams and lettering MUST be either computer drafted or drawn using India ink.

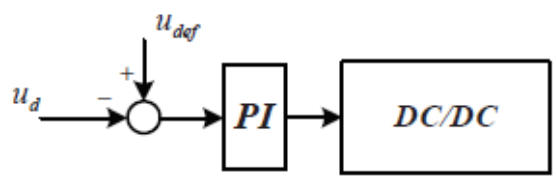

Fig 7. DC/DC Converter Control Strategy Scheme

\section{FUZZY LOGIC CONTROLLER}

The operation principle of a FL controller is similar to a human operator. It performs the same actions as a human operator does by adjusting the input signal looking at only the system output. A FL based controller consists of three sections namely fuzzifier, rule base and defuzzifier as shown in Fig 8. Two input signals, the main signal and its change for each sampling, to the FL controller are converted to fuzzy numbers first in fuzzifier. Then they are used in the rule table to determine the fuzzy number of the compensated output signal. Finally, the resultant united fuzzy subsets representing the controller output are converted to the crisp values. 


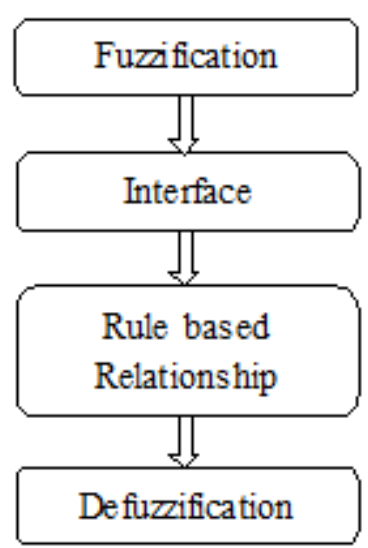

Fig 8. Step by Step Process of Fuzzy Logic Controller

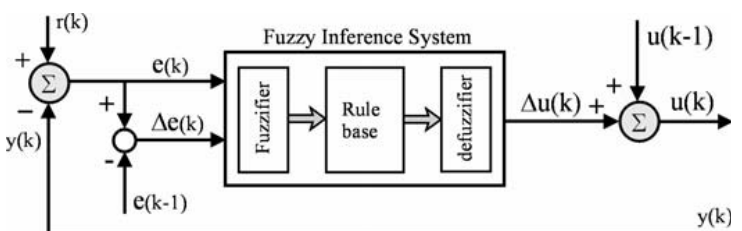

Fig 9. Basic structure of fuzzy logic based controller

Fuzzy rule decision table: The fuzzy rule base which may also be called as the fuzzy decision table is the unit mapping two crisp inputs $\mathrm{e}(\mathrm{k})$ and $\Delta \mathrm{e}(\mathrm{k})$ to the fuzzy output space defined on the universe of $\Delta \mathrm{u}(\mathrm{k})$.

Table 1: 25 Rule decision Table

\begin{tabular}{|c|c|c|c|c|c|}
\hline & \multicolumn{5}{|c|}{$\Delta e$} \\
\hline & $\mathrm{NB}$ & NS & ZL & PS & $P B$ \\
\hline $\mathrm{PB}$ & $Z Z 1$ & PS 2 & PS 3 & PB 4 & PB 5 \\
\hline$\overline{P S}$ & NS 6 & 727 & PS 8 & PS 9 & PB 10 \\
\hline $\mathrm{ZZZ}$ & NS 11 & NS 12 & ZZ 13 & PS 14 & PS 15 \\
\hline$\overline{\mathrm{NS}}$ & $\overline{\mathrm{NB} 16}$ & NS 17 & NS 18 & ZZ 19 & PS 20 \\
\hline $\mathrm{MB}$ & $\mathrm{NB} 21$ & $\mathrm{NB} 22$ & NS 23 & NS 24 & ZZ 25 \\
\hline
\end{tabular}

Choosing of the number of fuzzy subset depending on the required accuracy here we choose 7 subsets for increasing accuracy. The output $\Delta \mathrm{u}$ from the FL control is the change that is required to increase or decrease the overall control action to the controlled system. Therefore, the signs of e and $\Delta \mathrm{e}$ are used to determine the signs of $\Delta \mathrm{u}$ should be positive if $u$ is required to be increased and it should be negative otherwise. If e is zero THEN $\Delta$ taken the sign of $\Delta \mathrm{e}$, ELSE $\Delta \mathrm{u}$ takes the sign of e.

\begin{tabular}{|c|c|c|c|c|c|c|c|}
\hline $\begin{array}{l}\text { Error/C } \\
\text { hange } \\
\text { Error }\end{array}$ & NL & $\begin{array}{l}\mathrm{N} \\
\mathrm{M}\end{array}$ & NS & EZ & PS & $\begin{array}{l}\mathrm{P} \\
\mathrm{M}\end{array}$ & PL \\
\hline $\mathrm{NL}$ & NL & $\mathrm{NL}$ & $\mathrm{NL}$ & NL & $\begin{array}{l}\mathrm{N} \\
\mathrm{M}\end{array}$ & $\begin{array}{l}\mathrm{N} \\
\mathrm{S}\end{array}$ & $\begin{array}{l}E \\
Z \\
\end{array}$ \\
\hline NM & NL & NL & NL & $\begin{array}{l}\mathrm{N} \\
\mathrm{M}\end{array}$ & NS & $\begin{array}{l}E \\
Z \\
\end{array}$ & PS \\
\hline NS & NL & NL & $\begin{array}{l}\mathrm{N} \\
\mathrm{M}\end{array}$ & $\mathrm{NS}$ & $\mathrm{EZ}$ & PS & $\begin{array}{l}\mathrm{P} \\
\mathrm{M}\end{array}$ \\
\hline EZ & NL & $\begin{array}{l}\mathrm{N} \\
\mathrm{M}\end{array}$ & $\mathrm{NS}$ & EZ & PS & $\begin{array}{l}\mathrm{P} \\
\mathrm{M}\end{array}$ & PL \\
\hline PS & $\begin{array}{l}\mathrm{N} \\
\mathrm{M}\end{array}$ & NS & EZ & PS & $\begin{array}{l}\mathrm{P} \\
\mathrm{M}\end{array}$ & PL & PL \\
\hline PM & $\mathrm{NS}$ & EZ & PS & $\begin{array}{l}\mathrm{P} \\
\mathrm{M}\end{array}$ & $\mathrm{PL}$ & PL & PL \\
\hline PL & NL & $\begin{array}{l}\mathrm{N} \\
\mathrm{M}\end{array}$ & NS & EZ & PS & $\begin{array}{l}\mathrm{P} \\
\mathrm{M}\end{array}$ & PL \\
\hline
\end{tabular}

VI. SIMULATION RESULTS

The proposed concept is tested with two controllers namely

1. Proportional integral (PI) controller

2. Fuzzy logic controllers

The simulated results of faulty supply voltage, injected voltage and balanced load voltage with PI controller

The simulation results of energy storage based Unified Power Quality Conditioner with PI controller is illustrated in Fig 10.
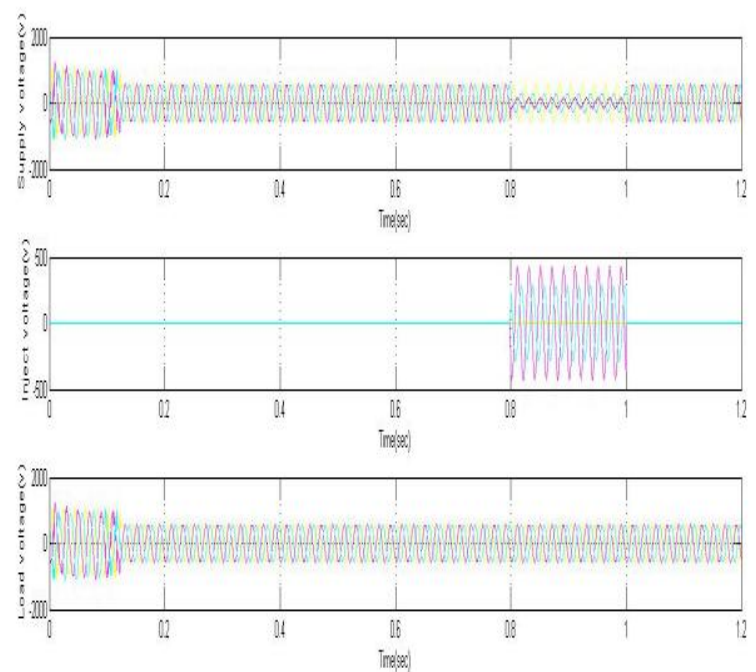

Fig 10. The simulated results of faulty supply voltage, injected voltage and balanced Load voltage with PI controller

The simulation results show the faulty 3 phase supply voltage and the injected voltage, compensated 3-phase load voltage of the proposed system. When these results are observed they shows transient nature and produces overshoots in their waveforms with PI controller .So due to these

Table 2: 49 Rule decision table 
transient nature and oscillatory response of the voltage with PI controller, rise time more and settling time also more to balance load voltage after the abnormal conditions.

Simulation results of faulty Source Voltage, injected Voltage, load Voltage with fuzzy Logic controller

The Fig 11 illustrates the Simulation results of faulty Source Voltage, injected Voltage load Voltage with fuzzy Logic controller, the results confirms that peak overshoots a transient nature of the supply and load voltages are die at faster rate when compared to fuzzy logic controller. So the fuzzy logic controller gives better performance when compared PI controller in the compensation of load voltage.
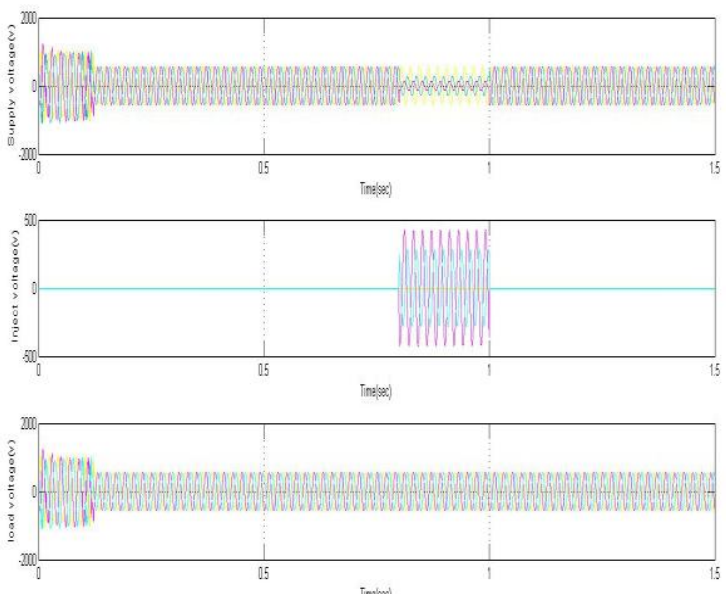

Fig 11. Simulation results of faulty Source Voltage, injected Voltage, load Voltage with fuzzy Logic controller

Comparison of Total harmonic distortion of source current with PI controller and Fuzzy logic controller

The Fig 12 shows the Total harmonic distortion analysis of the source current with PI controller, the THD value of the proposed concept with PI controller is $2.62 \%$. The source current needs sinusoidal so, the harmonic content of the source current has to be reduced further for this the proposed concept is tested with fuzzy logic controller.

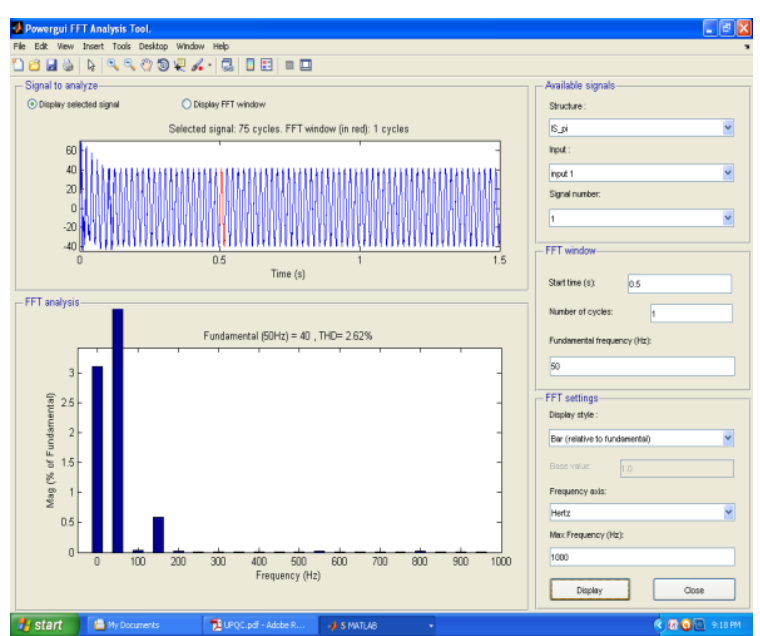

Fig: 12 The Total harmonic distortion analysis of the source current with PI controller

Fig 13 shows the total harmonic distortion of source current with fuzzy logic controller, the THD value of the source current with this concept is $0.86 \%$.so the THD value source current with FLC is less than PI controller and are presented in Table 3

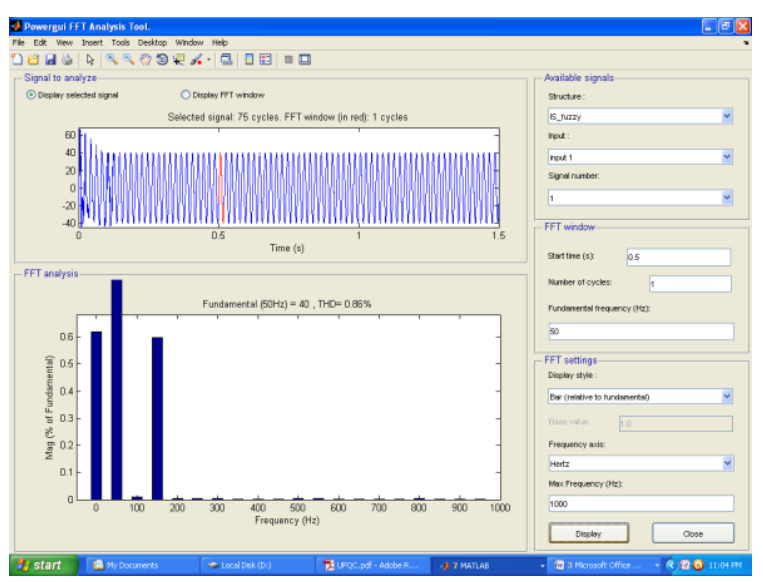

Fig 13 The Total harmonic distortion analysis of the source current with FLC controller

Table 3. Comparison of THD values of source current with PI and FL controllers

\begin{tabular}{|c|l|}
\hline $\begin{array}{l}\text { Percentage of total } \\
\text { harmonic distortion with } \\
\text { PI controllers }\end{array}$ & $\begin{array}{l}\text { Percentage of total } \\
\text { harmonic distortion with } \\
\text { FLC controllers }\end{array}$ \\
\hline 2.62 & 0.86 \\
\hline
\end{tabular}

\section{CONCLUSION}

This paper presents structure, principle and the control strategy of energy storage based unified power Quality Conditioner with fuzzy logic controllers and the PI controllers for an uncontrollable bridge rectifier with R-L load arrives at the following conclusions:

1. Super capacitor energy storage and DC/DC converter buffer reactive power exchange and 
provide energy support for voltage compensation. More over voltage quality problems of power interruption which are beyond the reach of conventional UPQC is resolved effectively in this thesis, which is a major problem in the distribution network with high infiltration of DGs.

2. The results obtained with the Fuzzy Logic controller is compared with those obtained using PI controller. The simulation results confirmed acceptable performances for the FLC. The purpose is not to compare the FLC with PI to see which gives better performance. But to observe whether the FLC gives acceptable results as PI controller does. However from the graphs and waveforms it is observed that the FLC gives lower transient magnitudes in system variables such as source current and voltage. So due to this improved performance of the fuzzy logic controllers the source current is nearer to sinusoidal nature. The reduction in the total harmonic distortion is also observed.

\section{REFERENCES}

[1] Libo han,Xingtian Feng,3Xiaoxu Che,Tongshuo Zhang,Tongzhen Wei in their study of "Unified Power Quality Conditioner Based on Fast Energy Storage".

[2] Nur Asyik Hidayatullah, Blagojce Stojcevski, Akhtar Kalam in their study of "Analysis of Distributed Generation Systems, Smart Grid Technologies and Future Motivators Influencing Change in the Electricity Sector".

[3] Ahmet teke1, Mehmet, Tumay1 in their study of "UPQC literature survey in $\mathrm{j}$ electrical Systems journal"

[4] Ismail H .Altas, Adel M.Sharaf in their thesis of "A Generalized direct approach for designing fuzzy logic controllers in matlab/simulink gui environment".

[5] RVD Rama rao, Dr.Subhransu Sekhar Dash in their thesis of "Enhancement of Power Quality by using Unified Power Quality Conditioner with PID and Fuzzy Logic Controller"

[6] "Power Electronics Circuits, Devices and Applications" by Muhammad Rashid

[7] "Generalised Theory Of Electrical Machines" By Dr.P.S Bimbra

[8] B.M han .b.Bae, "unified power Quality Conditioner with super capacitor for energy storage", European Tran. On electrical power, 18, 2007, 327-343.

[9] M. Hossini,H.A Shayanfar and M.F Firozabad , "Modeling of Unified power
Quality conditioner (UPQC) in distribution Systems load flow " Elsevier energy conversion and management 50,2009,15781585

[10] M.Davari,S.M ;Aleemran,H; Salabeigi,G.B,Gharehpetian, “ Modeling the combination of UPQC and photo voltaic arrays with multi input and single output $\mathrm{dc} / \mathrm{dc}$ converter" Industrial Technology ,IEEE Int.conference 2009,1-6.

[11] George "Artificial intelligence based three phase unified power Quality Conditioner ",Journal of computer Science 3(7),2007,465-477.

[12] "Modeling, Evaluation and Simulation of a Super Capacitor Module for energy Storage application" by A.B Cultura II , Z.M Salameh in International Conference on Computer Information Systems and industrial applications. 